\title{
Models of livestock production and conservation of animal genetic resources in the sustainable development system of rural Libya
}

\author{
Hashem Ahmed \\ Phd. candidate \\ DOI: $10.29322 /$ IJSRP.10.02.2020.p9806 \\ http://dx.doi.org/10.29322/IJSRP.10.02.2020.p9806
}

\begin{abstract}
In extensive pastoral systems, domestic animals are reared under extremely unfavorable agro-ecological conditions in Libya, from the early Neolithic to the Bronze Age, more than 8,000 years ago. As a result of free grazing, which in many cases exceeded the biomass production capacity as well as the dynamics of plant cover renewal, grassland vegetation has undergone major changes. Excessive grazing in the largest area has caused great damage not only to grasslands, but to other ecosystems in Libyan territory. The emergence of desertification in Libya is one consequence of this grassland resource management. Recent research over the last few decades, however, also points to the useful dimension of livestock farming for the environment, if managed properly.
\end{abstract}

Index

Terms-

Animals,agroecological,biomass, grasslands, environment,Libya.

\section{INTRODUCTION}

$\mathrm{T}$ The subject of this research is to explore the possibility of finding a more modern model of livestock production, with the possibility of preserving animal genetic resources as much as possible in the system of sustainable development of rural areas of Libya. All livestock production depends on food production, both on natural grassland, occupying about $8 \%$ of agricultural land in Libya, and on arable land (occupying only about $1 \%$ ). Large areas of natural grassland are on poor soil and in adverse climatic conditions. Agrotechnical repair measures are not applied on these surfaces, with more productive plant species disappearing with the use of free grazing. Altering the use and greater agro-technical investments would provide a greater amount of livestock feed, prevent erosion of these areas and preserve the system of ecological sustainability, which would raise the level of livestock production and production of food of animal origin. The survival of indigenous livestock species in modern livestock production in Libya is possible if breeding technology is up-to-date, both in terms of repairing the racial composition of the cattle so that new agricultural products are better adapted to market demands. From the point of view of animal production, it is necessary to find and define a new role for animal husbandry in the life of modern Libya. Modern livestock production, which provides greater market surpluses for food, will certainly make a major contribution to the development of Libya's rural areas.

\section{MAJOR ACTIVITIES IN THE WORLD RELATED TO THE MANAGEMENT AND CONSERVATION OF GENETIC RESOURCES}

The steady increase in population facing the world today requires the mobilization of all its resources to produce sufficient quantities of food. Animal resources have been promoted for greater and better production throughout the last century. In this way, a number of highly productive breeds were created, which could only show their production potential under much improved conditions of nutrition, housing and care. Newly created races became increasingly dependent on humans, and less and less resilient, and often could not survive in conditions in which the races from which they arose had previously resided without problems. All this has led to the disappearance of a large number of indigenous, ancient, primitive, low-yielding but highly resistant breeds of domestic animals in the world. The depopulation of mountainous areas, as well as the neglect and abandonment of livestock production in marginal areas, where high-yielding breeds could not be produced, also led to the disappearance of many breeds of domestic animals. In cattle breeding, the problem of preserving low-productive indigenous breeds of domestic animals is still difficult to explain and this fact makes it difficult to work on improving the use of animal genetic resources in practice. However, agro-diversity, including animal genetic resources, in the new concept of sustainable use of genetic resources, occupy a very important place, considering the natural potentials, economic and social environment, using world experience. The main activities in the world related to the management and conservation of genetic resources in the forward period should relate to:

1. Keying new conservation technologies,

2. Development of a publicly available breeder base for indigenous breeds,

3. Development of scientific research,

4. Work on capacity building of human and infrastructure,

5. Work on popularization (exhibitions of domestic animals, fairs, brochures, cooperation with the media),

6. Inclusion of indigenous breeds in organic production systems,

7. Development of a market for animated products of protected geographical origin obtained from indigenous races, 
8. Development of agro-tourism in protected areas, nature parks, continuation of cooperation at the global and regional level.

\section{CONSERVATION OF THE GENETIC RESERVES OF DOMESTIC} ANIMALS

There are several indigenous breeds of cattle, sheep, and poultry in Libya adapted to the climatic conditions as well as to the traditional farming conditions in the area. Indigenous breeds that are effectively cultivated in different ecosystems (forest, grazing), combined with the production of animal feed for their feed, bring not only the ability to conserve the genetic resources of these animals, but also an economically favorable environment for organizing cost-effective production and profit. Neglected livestock production in rural areas and the absence of grazing have threatened grasslands of high biodiversity value in Libya. Restoring the traditional way of breeding and grazing sheep, goats, cattle and horses in these fields would contribute not only to the restoration of plant biocenoses and their ability to survive, but also to the conservation and increase of native indigenous species from these areas. The conservation of the genetic reserves of domestic animals is done in one of the following ways:

1. In situ or on the farm - which means the conservation or cultivation of live animals in the production systems where they originated or are currently located, which equally include farms and production systems and

2. Ex situ - which means conservation outside the production systems where the animals lived, which may be:

a) In vivo breeding of live animals in zoos, nature parks, museums, research institutes and

b) In vitro cryopreservation of embryos, sperm, fertilized ova, deoxy-ribo-nucleic acid (DNA), somatic cells and other biological material that can be used for animal reconstruction.

\section{FARM ANIMAL GENOMIC RESOURCES - FANGR}

Domestic animal conservation practices are changing rapidly in light of policy developments, climate change and diversification of market demands. In recent decades, there has been a change in the technological and analytical approaches available to define, manage and conserve Farm Animal Genomic Resources (FAnGR). However, these rapid changes present challenges for conserving genetic resources in terms of technological continuity, analytical capacity and integrative methodologies needed to fully utilize new, multidimensional data. The final conference of the Genomic Resources ESF Program aimed to address these interdisciplinary problems in an effort to contribute to the planning of research and policy development guidance over the next decade. By 2020, under the Convention on

\footnotetext{
${ }^{1}$ Stéphane Joost, Michael W. Bruford, Ino Curik, Juha Kantanen, Johannes A. Lenstra, Johann Sölkner, Göran Andersson, Philippe V. Baret, Nadine Buys, Jutta Roosen, Michèle Tixier-Boichard, Paolo Ajmone Marsan, Advances in Farm Animal Genomic Resources, Frontiers Media SA, 2016
}

Biodiversity, signatories should ensure that the genetic diversity of farmed, farmed animals and wild relatives is maintained, and that strategies to minimize genetic erosion and maintain their genetic diversity are developed and implemented. The actual extent of genetic erosion is very difficult to measure using the available data. Therefore, this goal requires a better understanding and use of genomic and other data, the development of optimized ways of integrating this data with social and other sciences, and policy analysis to enable more flexible fact-based models to support the conservation of genetic resources. The conference identified the most important issues for the effective protection of genomic livestock animals over the next decade. Twenty priority issues have been identified that can be broadly categorized into challenges related to methodology, analytical approaches, data management. Many of the practical challenges facing the conservation of genomic resources are of social origin (socioeconomic and cultural) and based on the value of these resources to farmers, rural communities and society as a whole. Despite the fact that the livestock sector has been relatively well organized in the application of genetic methodologies to date, there is still a large gap between state-of-the-art technologies in the use of genomic resource characterization tools and their application to many non-commercial and local breeds that impede the consistent use of genetic and genomic data as indicators of genetic erosion and diversity. Therefore, the genomic sector of domestic animals must align to allow for the democratization of the powerful tools at their disposal and to ensure that they are applied in the context of race conservation and livestock development. ${ }^{1}$

Understanding current technical, infrastructural and policy challenges and assessing the potential benefits of overcoming them in the future is essential for any scientific field, and especially for those with clear social implications and potential benefits. In this context, a "horizon scanning concept" has been developed and has been applied annually in the field of biodiversity conservation since 2009 , using a series of systematic and semi-systematic methods for trend management, problem solving and analysis. ${ }^{2}$ Similar approaches have been taken to identify emerging problems in agriculture and related fields such as soil science, food systems and pollination. A number of issues of importance for the conservation of animal genetic resources have been identified, such as the genetic control of invasive species and the sustainable intensification of agricultural production. In their paper, Pretti and colleagues highlighted 100 of the most important issues that are important for the future of global agriculture, identifying genetic problems in crop improvement but not identifying similar issues for genomic resources of domestic animals. ${ }^{3}$ To fill this gap, the central activity of the European Science Foundation's Genomic Resources Program Conference, held at the University of Cardiff from 17 to 19 June 2014, was to select a series of questions that could be part of a research and policy agenda for FAnGR Conservation for the

${ }^{2}$ Sutherland, W.J., and Woodroof, H.J. 2009. The need for environmental horizon scanning. Trends in Ecology and Evolution: in press.

${ }^{3}$ Pretty, J., Brett, C., Gee, D., Hine, R. E., Mason, C. F.,Morison, J. I. L., Rayment, M., van der Bijl, G. \& Dobbs, T.2001 Policy challenges and priorities for internalising theexternalities of griculture.J. Environ. Planning Manage.4, 263-283 
Next Decade. During the conference, attendees were asked to contribute up to five top priority research, infrastructure and policy development questions over the next decade. Eighty-six proposals were accepted. An issue identified with the highest frequency (18 times) was the need to "phenotype the next generation" (highthroughput methods for collecting and summarizing detailed phenotypic data in domestic animals). All answers are categorized into four main groups:

1. methodological challenges,

2. analytical challenges,

3. data management and

4. protection management and prioritization.

The need to collect phenotype data has been identified to perform in-depth characterization of the genetic resources of domestic animals, especially in light of the progress made in characterizing the breed at the molecular level. Developing methods for phenotypic characterization were identified following FAO recommendations, but remained an under-researched area of research. ${ }^{4}$ With the abundance of molecular data increasing dramatically since 2009, there is a growing mismatch between molecular and phenotypic data for all domestic animal resources except for highly commercial breeds and breeds of high breeding values. In accordance with the characteristics of the highresolution breed, key phenotypic traits (especially those potentially involved in local adaptation) need to be defined based on guidelines that can be used as common measures for such studies with rigorous collection protocols. FAO has published guidance on phenotypic characterization. ${ }^{5}$ In this way more comparable data can be generated and race characterization can have better functional bases, especially to understand the required breeding characteristics in light of climate change. An improved description of the specific production environment and epidemiological history of the breed population would allow a better comparison of the phenotypes and performance of the individuals. Race characterization can be expensive, especially in remote regions, and given well-documented and reproducible procedures, many phenotypic traits need to be collected, a process that requires the need for standardized methods for measuring and collecting data, as well as training people how to they work. Where possible, data should be made publicly available, such as, for example, the DAD-IS Global Animal Diversity Information System for comparative purposes. ${ }^{6}$

Reference genomes provide the basis for the development of genome variations in small farm cases and / or for multiple

\footnotetext{
${ }^{4}$ Stéphane Joost, Michael W. Bruford, Ino Curik, Juha Kantanen, Johannes A. Lenstra, Johann Sölkner, Göran Andersson, Philippe V. Baret, Nadine Buys, Jutta Roosen, Michèle Tixier-Boichard, Paolo Ajmone Marsan, Advances in Farm Animal Genomic Resources, Frontiers Media SA, 2016

${ }^{5}$ http://www.fao.org/3/a-i3028e.pdf

${ }^{6} \mathrm{http}: / /$ dad.fao.org

${ }^{7}$ Meadows J. R. S., Kijas J. W. (2008). Re-sequencing regions of the ovine $\mathrm{Y}$ chromosome in domestic and wild sheep reveals novel paternal haplotypes. Anim. Genet. 40, 119-123.

${ }^{8}$ Pereira F., Queirós S., Gusmão L., Nijman I. J., Cuppen E., Lenstra J. A., et al. . (2009). Tracing the history of goat
}

livestock species and populations using SNP methods (Single Nucleotide Polymorphisms), which have been developed and available to commercial livestock farmers over the past 10 years and are applicable and in Libya. Currently, no SNP strand methods are applied in Libya, so consideration should be given to introducing them into the development of genetic potential in domestic animals, especially indigenous breeds, on this topic. It is important to note that with the rapid decline in the cost of genome research, the availability of newer generation technologies (which require less cost than genotyping via sequencing - GBS) is increasingly being used worldwide, and the problem of bias in genome research can be mitigated as identification and direct assessment of the diversity of SNP arrays for populations, races, or species by FAnGR.

The depletion of genetic resources is the result of changes and (inadequate) development of agriculture and livestock in the world. There is an inevitable conflict between the desire to conserve diverse genetic resources and the need to increasingly focus on a narrow range of genotypes in the interest of more efficient livestock production. Due to the competitive nature of livestock farming, it is clear in certain circumstances that more productive individuals, strains or breeds will replace less productive ones. However, this attitude is influenced by three main factors. First, production circumstances and market demands vary across the globe. Second, in any set of production and market conditions, requirements change over time. The third factor can be called the insurance factor. While short-term trends in the livestock system are obvious, we cannot accurately predict requirements after several decades in the future. Moreover, the actual genetic heritage of most races and species in the world is only superficially observed. There may be genes and / or gene combinations that are of great value, but are completely unknown today.

Non-autosomal inheritance (I-chromosome, X-chromosome and mitochondrial) is a comparatively neglected area of research in livestock protection. Although studies of non-autosomal genetic markers have been extensively used in evolutionary history studies, both individually and in combination, their exploitation in genomic studies has been neglected compared to autosomal markers in many livestock species. ${ }^{7} 89$ This control is surprising given the well-documented links between mitochondrial sequence variation in the human population ${ }^{10}$, and the role that Ichromosomal variations play in the fertility of male cattle is

pastoralism: new clues from mitochondrial and Y chromosome DNA in North Africa. Mol. Biol. Evol. 26, 2765-2773.

${ }^{9}$ Sanderson M. A., Archer D., Hendrickson J., Kronberg S., Liebig M., Nichols K., et al. (2013). Diversification and ecosystem services for conservation agriculture: outcomes from pastures and integrated crop-livestock systems. Renew. Agric. Food Syst. 26, 129-144.

${ }^{10}$ Wallace D. C. (2005). A mitochondrial paradigm of metabolic and degenerative disease, aging and cancer: a dawn for evolutionary medicine. Ann. Rev. Genet. 39, 359-407. 
increasingly recognized..$^{11}$ The invention of polymorphic markers on the I-chromosome in mammals and V-chromosomes in birds has given new insights into the diversity of livestock ${ }^{12}$, and should be used as a subject to provide a perspective on the genomic diversity of livestock.

Although firmly established as a major pathway into a deeper understanding of the evolution and diversity of livestock, research on old DNA (aDNA) is limited. ${ }^{13}$ These include limited access to samples from geographical areas where they may exist (locally) (e.g., Africa, Middle East, Asia, South America), limited data sharing among groups working on samples from critical locations, and limited success rates, especially in studies at genome level. ${ }^{14}$ Nonetheless, methodological and bioinformatics tools have recently been developed that have enabled greater accuracy in the analysis of ancient DNA data and characterization of complete genomes of Pleistocene horses. ${ }^{15}$ The most interesting possibilities were recently opened with the discovery of ancient DNA of cattle in the sediments of Lake Anterne in Switzerland, which allowed a direct comparison of all changes in this environment from the appearance of first specimens to modern domestic livestock. ${ }^{16}$ These findings could be applied in describing the historical fluctuation in agricultural intensity and may even allow for predictive modeling of the presence or absence of suitable agro-habitat in future climate change scenarios.

The concept of genome preservation has been widely researched in the literature, but advances in the amount of data and genome technologies now allow the development of livestock management programs that could achieve this goal. For example, Herrero-Medrano et al. (2014) used genome-wide reaction and SNP arrays and found that about one hundred non-synonymous

${ }^{11}$ Wu H., Guang X., Al-Fageeh M. B., Cao J., Pan S., Zhou H., et al. . (2014). Camelid genomes reveal evolution and adaptation to desert environments. Nat. Commun. 5, 5188.

${ }^{12}$ Edwards C. J., Ginja C., Kantanen J., Perez-Pardal L., Tresset A., Stock F., et al. . (2011). Dual origins of dairy cattle farming evidence from a comprehensive survey of European Y-

chromosomal variation. PLoS ONE 6:e15922

${ }^{13}$ Larson G., Lui R., Zhao X., Yuan J., Fuller D., Barton L., et al. . (2010). Patterns of East Asian pig domestication, migration, and turnover revealed by modern and ancient DNA. Proc. Natl. Acad. Sci. U.S.A. 107, 7686-7691.

${ }^{14}$ Arbuckle B. S., Kansa S. W., Kansa E., Orton D., Çakirlar C., Gourichon L., et al. . (2014). Data sharing reveals complexity in the westward spread of domestic animals across Neolithic

Turkey. PLoS ONE 9:e99845. 10.1371

${ }^{15}$ Orlando L., Ginolhac A., Zhang G., Froese D., Albrechtsen A., Stiller M., et al. . (2013). Recalibrating Equus evolution using the genome sequence of an early Middle Pleistocene horse. Nature 499, 74-78

${ }^{16}$ Giguet-Covex C., Pansu J., Arnaud F., Rey P.-J., Griggo C., Gielly L., et al. . (2014). Long livestock farming history and human landscape shaping revealed by lake sediment DNA. Nat. Commun. 5, 3211. 10.1038

${ }^{17}$ Herrero-Medrano J.-M., Megens H.-J., Groenen M. A. M., Boss M., Pérez-Enciso M., Crooijmans R. P. M. A. (2014). Whole-genome sequence analysis reveals differences in population management and selection of European low-input pig breeds. BMC Genomics 15:601. polymorphic nucleotides were fixed in domestic pigs, but with an alternative allele in non-commercial populations, affecting a total of 65 genes. ${ }^{17}$ Such genomic polymorphisms may fall into the category of those that should not be lost to less commercial local breeds, given their specificity and the value they potentially represent as a genetic resource for alternative selection if the environment changes. ${ }^{18}$ However, to design a management program that evaluates genomic regions for conservation, not only are polymorphisms identified, but it is also necessary to evaluate the functional architecture of those genomic regions and the genes they contain, as well as the interactions between those genes. Recently, research on one species of chickens examined the functional variation of copy number variants (CNVs) on over 200 genes overlapping with 1000 quantitative loci, including some that were involved in traits such as skin color and skeletal characteristics. ${ }^{19}$ Obtaining an accurate description of genetic polymorphisms that explain a trait of evolutionary, adaptive, and / or economic significance is not at all an insignificant task, since traits differ significantly in the number of polymorphisms included in their phenotype where they occur across the genome. ${ }^{20}{ }^{21}$ For example, many such traits are polygenic and distributed around the genome, making whole genome responsive, and medium- and high-density SNPs allocate access to locate and elucidate their variation. $^{22}$ However, for certain related traits, haplotypes can provide a more efficient assessment of diversity in KTL regions than single SNPs, reflecting the local genomic architecture in a more precise way. ${ }^{23}{ }^{24}$ Accordingly, in the initial stages of studies aimed at identifying the genetic underpinnings of phenotypic variation, genome-wide general SNP analyzes may be more appropriate. It is important to note, however, that phase haplotypes

${ }^{18}$ Kristensen T. N., Hoffmann A. A., Pertoldi C., Stronen A. V. (2015). What can livestock breeders learn from conservation genetics and vice versa? Front. Genet. 6:38. 10.3389

${ }^{19}$ Han R., Yang P., Tian Y., Wang D., Zhang Z., Wang L., et al. . (2014). Identification and functional characterization of copy number variation in diverse chicken breeds. BMC Genomics 15:934. 10.1186/1471-2164-15-934

${ }^{20}$ Goddard M. T., Hayes B. J. (2009). Mapping genes for complex traits in domestic animals and their use in breeding programs. Nat. Rev. Genet. 10, 381-391.

${ }^{21}$ Olson-Manning C. F., Wagner M. R., Mitchell-Olds T. (2012). Adaptive evolution: evaluating empirical support for theoretical predictions. Nat. Rev. Genet. 13, 867-877

${ }^{22}$ Huang W., Kirkpatrick B. W., Rosa G. J. M., Khatib H. (2010). A genome-wide association study using selective DNA pooling identifies candidate markers for fertility in Holstein cattle. Anim. Genet. 41, 570-578.

${ }^{23}$ Kijas J. W., Ortiz J. S., McCulloch R., James A., Brice B., Swain B., et al. . (2013). Genetic diversity and investigation of polledness in divergent goat populations using 52088 SNPs. Anim. Genet. 44, 325-335.

${ }^{24}$ Bosse M., Megens H. J., Madsen O., Frantz L. A., Paudel Y., Crooijmans R. P., et al. . (2014a). Untangling the hybrid nature of modern pig genomes: a mosaic derived from biogeographically distinct and highly divergent Sus scrofa populations. Mol. Ecol. 23, 4089-4102. 
in different populations that lack complementary data are challenging. Haplotype analysis can provide a particularly powerful tool for exploring the hybrid origins of native populations. For example, modern Western commercial porcine genes are a combination of Eastern and Western Eurasian biogeographical origins. Administration mapping permits the "sorting" of haplotype segments by their origin. In addition, this strategy has been shown to be good for concluding selection on specific haplotypes after hybridization. ${ }^{25}$

The transition from microsatellite markers to SNP arrays was quickly accomplished (at Farm Animal Genetic Resources FAnGR) for commercial / transboundary breeds due to the availability of relatively inexpensive SNP genotypes for the most common livestock species. However, SNP arrays are not yet affordable tools for most FAnGRs in the world and are not yet available for all species. So there is a problem how to integrate data from two types of markers and how to manage the transition from microsatellite-based FAnGR characterization (most of which were done using markers recommended by the International Society for Animal Genetics - ISAG based on SNP-based characterization. ${ }^{26}$ One option is to replicate the genotype of a number of races that already have microsatellite genotypes with SNP arrays, but this would be expensive and if asked, the question would be whether new data would be replaced with newer technologies (eg whole genome sequencing). ${ }^{27}$ As a rule, microsatellite data appear to be sufficiently adequate to assess genetic diversity and be able to describe demographic relationships. However, because of cost, the entire set of microsatellite markers is often not applied, especially in developing countries. Also, microsatellite data are not as efficient as to enable identification and targeted conservation of selected genomic regions, since the data is usually obtained from several dozen quasi-neutral markers. ${ }^{28}$ However, it becomes clear that the data produced using SNP arrays are more reproducible and are not affected by the differences that once caused the combination of microsatellite datasets and required statistical estimation. ${ }^{29}$ Whole-genome reaction can become the most reliable and cheapest way to analyze genomic diversity in the future, even for non-commercial breeds, if the cost of testing is reduced (which can happen with portable sequencers like Oxford Nanopore's MiniION system) $)^{30}$, as they no longer have to use the SNP marker sets established in commercial populations.

Creating models of livestock production and conservation of animal genetic resources in the sustainable development system of rural Libya

\footnotetext{
${ }^{25}$ Bosse M., Megens H. J., Frantz L. A., Madsen O., Larson G., Paudel Y., et al. . (2014b). Genomic analysis reveals selection for Asian genes in European pigs following human-mediated introgression. Nat. Commun. 5, 4392. 10.1038

${ }^{26}$ FAO (2011). Molecular Genetic Characterization of Animal Genetic Resources. FAO Animal Production and Health Guidelines. No. 9. Rome.

${ }^{27}$ Ajmone-Marsan P., Colli L., Han J., Achilli A., Lancioni H., Joost S., et al. (2014). The characterization of goat genetic diversity: towards a genomic approach. Small Ruminant. Res. $121,58-72$
}

Libya has a large and diverse reservoir of animal genetic resources, most of which are indigenous and classified according to the communities and regions in which they are located. Pastoral communities in Libya predominantly have their own indigenous breeds of domestic animals whose contribution to life can still be improved if the genetic basis is improved. Some of the basic sheep species in Libya are: Barki, Sicilo-Sarde, Maur, Tuareg, Abidi, etc. Some of the goats are Mahali, Targhai, Tebawi, etc. In Libya, as well as throughout northern Africa, the most widespread species of cattle are Humpless Shorthorn cattle (Bos taurus). Creating a model for livestock production and conservation of animal genetic resources in Libya's rural development system is not static and its dynamic dimension needs to be aligned with the environmental and sustainable development challenges and as such can be of benefit to agricultural policy makers as well as those who are in charge of professional development of employees (and shepherds) in farm systems. Model development should be preceded by research into the causes that led to the erosion and loss of genetic diversity of domestic animals in Libya, namely:

1. introduction of exotic breeds into production,

2. limiting development to only a few races,

3. changes in market requirements,

4. ecosystem degradation and

5. natural disasters.

The main activities related to the management and conservation of genetic resources in Libya in the coming period should relate to:

1. The incorporation of new conservation technologies (primarily ex situ),

2.Development of a publicly available breeder base for indigenous breeds

3. Development of scientific research,

4. Capacity building work (human and infrastructure),

5. Popularization work (domestic animal exhibitions, fairs, brochures, cooperation with media),

6. Inclusion of indigenous breeds in organic production systems,

7. Development of a market for animated products of protected geographical origin obtained from indigenous races,

8. Development of agro-tourism in protected areas and nature parks,

9. Continuing Libya's global and regional cooperation.

\section{The goals of farming livestock to serve farmers across Libya}

Analyzing all of these resource constraints, the problems and the possible lack of funding for genetic resources conservation

\footnotetext{
${ }^{28}$ Herrero-Medrano J.-M., Megens H.-J., Groenen M. A. M., Boss M., Pérez-Enciso M., Crooijmans R. P. M. A. (2014). Whole-genome sequence analysis reveals differences in population management and selection of European low-input pig breeds. BMC Genomics 15:601. 10.1186

${ }^{29}$ Lenstra J. A., Groeneveld L. F., Eding H., Kantanen J., Williams J. L., Taberlet P., et al. . (2012). Molecular tools and analytical approaches for the characterization of farm animal genetic diversity. Anim. Genet. 43, 483-502.

${ }^{30}$ Izvor: https://nanoporetech.com/
} 
programs in Libya signal that the breeding strategy will not be easy to determine. However, I believe that improving the overall herd management system (feeding, housing, health care and breeding) combined with the introduction of a basic monitoring scheme can improve the performance of domestic animal breeds in Libya. The most important advantage is the availability of a relatively closed livestock population adapted to the existing environment that overcomes the structural problem of small herd size. In addition, setting up local government offices to improve livestock species is another important issue that has prompted us to propose a practical breeding scheme. We therefore propose that the "closed selection" model be operationally integrated with the local production environment in Libya. This scheme should build on the current breeding structure and animals. With regard to biophysical grazing, I think the Australian model "GrassGro" would be most appropriate for the conditions in Libya as it is widely used in pastures where the key issues that are the best time for lambing / calving are key. This model is able to quantify variability in pastures and animal production in response to pronounced climate change, so that farmers and natural resource managers in Libya can assess the impact of profitability and risk of changing weather or management system variables. The model should use daily data on climatic conditions and grazing characteristics (soil characteristics, moisture holding capacity, type of pasture), animals (including genotypes), pasture management systems (including rules for feeding animals). Seasonal and annual variations in pasture and animal production make it possible to analyze the risks associated with climate change or management decisions.

The goal of farming livestock is to serve farmers across Libya more broadly. Breeding goals should focus on saving input resources, achieving breeding sustainability, dynamic genetic enhancements and adjusting to the local production environment. Diversification of breeding objectives should be in line with local production environments to help preserve diversity in genetic resources, which will also support genetic improvement of the herd. In addition, I propose that the goal of raising domestic animals in Libya (sheep, goats, camels) is to increase the yield of products such as milk and meat. Goals should be based on previously identified traits of the herd. These traits, if not easily measured, must have a high genetic correlation with desirable economic value, be they goods or a means of reducing production costs. In other words, an increase in milk yield can bring in additional income, for example from the sale of cheese. More milk production means a better survival rate for the cubs

Furthermore, it should be noted that the reproduction rate in most tropical cattle species is low. Nevertheless, this trait is very important not only in the economics of production but also in genetic enhancement because of the effect on selection intensity. The elimination of low fertility animals can improve fertility in the rest of the livestock population. Reproduction intervals in cows can be improved to some extent by improved nutrition and improved health status in domestic animals. Adaptation to disease is another trait to choose for genetically enhancing breeds, although developing disease-resistant breeds is not an easy task, and it takes time and the mobilization of great resources. So, a more practical way is to concentrate on the selection of production traits over the environment, which will allow the selected animals to better adapt. Finally, longevity in terms of length of productive herd life (for example, number of calves / cows) was identified as the desired target. This is certainly important, as animals that stay longer in production help reduce costs. Animals with longer productive lives should be identified so that their close relatives can be selected. For marginal areas, the long-term reproductive effects of female individuals will then be of greater value. Although the introduction of exotic breeds plays an important role in increasing livestock production, their use must be rationalized, and the dissemination of their genetic material must be under the constant control of the competent institutions in Libya.

\section{CONCLUSION}

Libya and the whole region of North Africa suffer from the serious effects of climate change. Severe recurrences and other natural disasters cause widespread hunger, environmental degradation, poverty and economic hardship in Libya and the region. The impact of climate change is high due to inadequate water management facilities and poor water supply practices, inefficient and outdated water production plants, unstable and unpredictable rainfall patterns and high temperatures. Their consequences include lack of water and food for animals and humans, leading to a high incidence of hunger and loss of life for humans and animals in the region. In order to overcome this nutritional deficiency, Libya must import large quantities of food. Such a level of dependence on food imports is not sustainable and can turn into a humanitarian tragedy that threatens not only to endanger peace but also to the preservation of a unique environment and biodiversity, as well as the ability for Libya to play a more important role in an increasingly global environment. Water and pastures are critical for improving animal production and productivity. Unfortunately, Libya, as noted above, suffers from a severe lack of both of these factors. Pastoral lifestyles are characterized by frequent changes of location in search of water and food during long periods of scarcity. The availability of water, along with its quality, is also important for human consumption. The scarcity of natural resources, especially water and pastures, has led to fierce conflicts in the past, which may soon resurface due to food shortages and poverty. Shepherds and agro-shepherds live in extreme poverty with limited alternative sources of income and in constant mobility in search of water and food for their livestock and their livelihoods. There is a need to develop different strategies to intervene in such sensitive environments in order to improve rural life, increase food security and improve natural resource management.

Libya is a country with more than $94 \%$ of the desert, a narrow Mediterranean coast and a vast expanse of arid regions. There are 2103 species belonging to 856 genera and 155 families in Libya. The floristic command in Libya reflects the plant's strategy to resist the yellow weather. The distribution of life forms between Libyan plants is characterized by a high percentage of plants (net to perennial) and a low number of woody (trees and shrubs) species. They reflect the defense capabilities of vegetation in such drought conditions. The geographical elements of the Libyan flora are dominated by the Mediterranean Sea and the Sahara Desert. The floristic elements and distribution characteristics also indicate that climatic and enormous conditions, ecological amplitude and adaptive capacity of the 
plants influenced the floristic origin and spatial patterns of plant diversity. Forms of plant communities can be a functional tool for ecological restoration. Therefore, native species should be used for cultivation and regional vegetation should be used during the ecological recovery and rehabilitation process. We hope to develop a predictive understanding of the structure and function of plant ecosystems to provide insight. Libya is rich in livestock genetic resources and great diversity, both phenotypically and genetically. Efforts to better manage and utilize these resources are weak or non-existent due to the weakness of government institutions. Most of these institutions not only lack financial and human resources, but there is also no enthusiasm to drive action.

\section{REFERENCES}

[1] Ajmone-Marsan P., Colli L., Han J., Achilli A., Lancioni H., Joost S., et al. (2014). The characterization of goat genetic diversity: towards a genomic approach. Small Ruminant. Res. 121, 58-72.

[2] Andersson, Philippe V. Baret, Nadine Buys, Jutta Roosen, Michèle TixierBoichard, Paolo Ajmone Marsan, Advances in Farm Animal Genomic Resources, Frontiers Media SA, 2016

[3] Arbuckle B. S., Kansa S. W., Kansa E., Orton D., Çakirlar C., Gourichon L., et al. . (2014). Data sharing reveals complexity in the westward spread of domestic animals across Neolithic Turkey. PLoS ONE 9:e99845. 10.1371

[4] Barbato M., Orozco-terWengel P., Tapio M., Bruford M. W. (2015). SNeP: a tool to estimate trends in recent effective population size trajectories using genome-wide SNP data. Front. Genet. 6:109.

[5] Bosse M., Megens H. J., Frantz L. A., Madsen O., Larson G., Paudel Y., et al. . (2014b). Genomic analysis reveals selection for Asian genes in European pigs following human-mediated introgression. Nat. Commun. 5, 4392. 10.1038

[6] Bosse M., Megens H. J., Madsen O., Frantz L. A., Paudel Y., Crooijmans R. P., et al. . (2014a). Untangling the hybrid nature of modern pig genomes: a mosaic derived from biogeographically distinct and highly divergent Sus scrofa populations. Mol. Ecol. 23, 4089-4102.

[7] Curik I., Ferencakovic M., Soelkner J. (2014). Inbreeding and runs of homozygosity: a possible solution to an old problem. Livestock Sci. 166, $26-$ 34.

[8] Edwards C. J., Ginja C., Kantanen J., Perez-Pardal L., Tresset A., Stock F., et al. . (2011). Dual origins of dairy cattle farming - evidence from a comprehensive survey of European Y-chromosomal variation. PLoS ONE 6:e15922

[9] FAO (2011). Molecular Genetic Characterization of Animal Genetic Resources. FAO Animal Production and Health Guidelines. No. 9. Rome.

[10] Ferrando A., Goyache F., Pares P.-M., Carrion C., Miro J., Jordana J. (2014). Genetic relationships between six eastern Pyrenean sheep breeds assessed using microsatellites. Spanish J. Agric. Res. 12, 1029-1037.

[11] Frantz L. A. F., Madsen O., Megens H.-J., Schraiber J. G., Paudel Y., Bosse M., et al. . (2015). Evolution of Tibetan wild boars. Nat. Genet. 47, 188-189.

[12] Giguet-Covex C., Pansu J., Arnaud F., Rey P.-J., Griggo C., Gielly L., et al. . (2014). Long livestock farming history and human landscape shaping revealed by lake sediment DNA. Nat. Commun. 5, 3211. 10.1038

[13] Goddard M. T., Hayes B. J. (2009). Mapping genes for complex traits in domestic animals and their use in breeding programs. Nat. Rev. Genet. 10, 381-391.

[14] Han R., Yang P., Tian Y., Wang D., Zhang Z., Wang L., et al. . (2014). Identification and functional characterization of copy number variation in diverse chicken breeds. BMC Genomics 15:934. 10.1186/1471-2164-15-934.

[15] Herrero-Medrano J.-M., Megens H.-J., Groenen M. A. M., Boss M., PérezEnciso M., Crooijmans R. P. M. A. (2014). Whole-genome sequence analysis reveals differences in population management and selection of European low-input pig breeds. BMC Genomics 15:601.

[16] http://dad.fao.org

[17] http://www.fao.org/3/a-i3028e.pdf
[18] https://nanoporetech.com/

[19] Huang W., Kirkpatrick B. W., Rosa G. J. M., Khatib H. (2010). A genomewide association study using selective DNA pooling identifies candidate markers for fertility in Holstein cattle. Anim. Genet. 41, 570-578.

[20] Kijas J. W., Ortiz J. S., McCulloch R., James A., Brice B., Swain B., et al. (2013). Genetic diversity and investigation of polledness in divergent goat populations using 52088 SNPs. Anim. Genet. 44, 325-335.

[21] Kristensen T. N., Hoffmann A. A., Pertoldi C., Stronen A. V. (2015). What can livestock breeders learn from conservation genetics and vice versa? Front. Genet. 6:38. 10.3389

[22] Larson G., Lui R., Zhao X., Yuan J., Fuller D., Barton L., et al. . (2010) Patterns of East Asian pig domestication, migration, and turnover revealed by modern and ancient DNA. Proc. Natl. Acad. Sci. U.S.A. 107, 7686-7691.

[23] Lenstra J. A., Groeneveld L. F., Eding H., Kantanen J., Williams J. L., Taberlet P., et al. . (2012). Molecular tools and analytical approaches for the characterization of farm animal genetic diversity. Anim. Genet. 43, 483-502.

[24] Meadows J. R. S., Kijas J. W. (2008). Re-sequencing regions of the ovine Y chromosome in domestic and wild sheep reveals novel paternal haplotypes. Anim. Genet. 40, 119-123.

[25] Olson-Manning C. F., Wagner M. R., Mitchell-Olds T. (2012). Adaptive evolution: evaluating empirical support for theoretical predictions. Nat. Rev. Genet. 13, 867-877

[26] Orlando L., Ginolhac A., Zhang G., Froese D., Albrechtsen A., Stiller M., et al. . (2013). Recalibrating Equus evolution using the genome sequence of an early Middle Pleistocene horse. Nature 499, 74-78.

[27] Orozco-terWengel P. A., Bruford M. W. (2014). Mixed signals from hybrid genomes. Mol. Ecol. 23, 3941-3943.

[28] Pereira F., Queirós S., Gusmão L., Nijman I. J., Cuppen E., Lenstra J. A., et al. . (2009). Tracing the history of goat pastoralism: new clues from mitochondrial and Y chromosome DNA in North Africa. Mol. Biol. Evol. 26 2765-2773.

[29] Porto Neto L. R., Barendse W. (2010). Effect of SNP origin on analyses of genetic diversity in cattle. Anim. Prod. Sci. 50, 792-800.

[30] Pretty, J., Brett, C., Gee, D., Hine, R. E., Mason, C. F.,Morison, J. I. L., Rayment, M., van der Bijl, G. \& Dobbs, T.2001 Policy challenges and priorities for internalising theexternalities of griculture.J. Environ. Planning Manage.4, 263-283

[31] Pryce J. E., Haile-Mariam M., Goddard M. E., Hayes B. J. (2014). Identification of genomic regions associated with inbreeding depression in Holstein and Jersey dairy cattle. Genet. Sel. Evol. 46:71.

[32] RNP Conservation Genomics, dostupno na: https://www.ru.nl/congenomics/

[33] Sanderson M. A., Archer D., Hendrickson J., Kronberg S., Liebig M., Nichols K., et al. (2013). Diversification and ecosystem services for conservation agriculture: outcomes from pastures and integrated crop-livestock systems. Renew. Agric. Food Syst. 26, 129-144.

[34] Scraggs E., Zanella R., Wojtowicz A., Taylor J. F., Gaskins C. T., Reeves J. J., et al. . (2014). Estimation of inbreeding and effective population size of full-blood wagyu cattle registered with the American Wagyu Cattle Association. J. Anim. Breed. Genet. 131, 3-10.

[35] Andersson, Philippe V. Baret, Nadine Buys, Jutta Roosen, Michèle TixierBoichard, Paolo Ajmone Marsan, Advances in Farm Animal Genomic Resources, Frontiers Media SA, 2016

[36] Sutherland, W.J., and Woodroof, H.J. 2009. The need for environmental horizon scanning. Trends in Ecology and Evolution: in press.

[37] Wallace D. C. (2005). A mitochondrial paradigm of metabolic and degenerative disease, aging and cancer: a dawn for evolutionary medicine. Ann. Rev. Genet. 39, 359-407.

[38] Wu H., Guang X., Al-Fageeh M. B., Cao J., Pan S., Zhou H., et al. . (2014) Camelid genomes reveal evolution and adaptation to desert environments. Nat. Commun. 5, 5188.

\section{AUTHORS}

First Author - Hashem Ahmed ,Phd. candidate 
